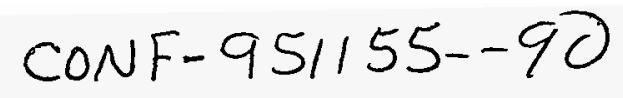

\title{
HUMID-AIR AND AQUEOUS CORROSION MODELS FOR CORROSION- ALLOWANCE BARRIER MATERIAL
}

J.H. Lee, J.E. Atkins and R.W. Andrews

INTERA, Inc./CRWMS M\&O

101 Convention Center Drive, Suite P-110, Las Vegas, NV 89109, USA

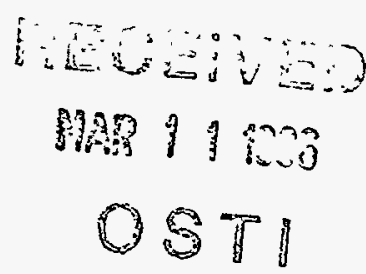

Humid-air and aqueous general and pitting corrosion models (including their uncertainties) for the carbon steel outer containment barrier were developed using the corrosion data from literature for a suite of cast irons and carbon steels which have similar corrosion behaviors to the outer barrier material. The corrosion data include the potential effects of various chemical species present in the testing environments. The atmospheric corrosion data also embed any effects of cyclic wetting and drying and salts that may form on the corroding specimen surface. The humid-air and aqueous general corrosion models are consistent in that the predicted humid-air general corrosion rates at relative humidities between 85 and $100 \% \mathrm{RH}$ are close to the predicted aqueous general corrosion rates. Using the expected values of the model parameters, the model predicts that aqueous pitting corrosion is the most likely failure mode for the carbon steel outer barrier, and an earliest failure (or initial pit penetration) of the 100 -mm thick barrier may occur as early as about 500 years if it is exposed continuously to an aqueous condition at between 60 and $70^{\circ} \mathrm{C}$.

\section{INTRODUCTION}

The current design concept of a multi-barrier waste container for the disposal of the nation's high-level nuclear waste in the potential repository at Yucca Mountain, Nevada, calls for a thick layer (about $100 \mathrm{~mm}$ ) of carbon steel corrosion-allowance material (CAM) as the outer barrier, and a thin layer (about $20 \mathrm{~mm}$ ) of Alloy 825 corrosion-resistant material (CRM) as the inner barrier. The initial post-closure near-field environment of the potential repository will be hot and dry, and following the peak temperature period, the near-field environment would cool down gradually. Thus, the waste containers are expected to undergo humid-air corrosion initially at elevated temperatures, and their corrosion mode will gradually shift to aqueous corrosion as the near-field environment continues to cool down to lower temperatures and more humid conditions. This paper discusses the general and pitting corrosion models for CAM in humid-air and aqueous conditions, which were developed for the total system performance assessment-1995 (TSPA-1995) [1]. The models will be improved (or refined) as more site-relevant corrosion data become available.

\section{HUMID-AIR CORROSION MODELS}

\section{Corrosion Data Compilation}

A total of 166 atmospheric corrosion data (up to 16 years) of cast irons and carbon steels which have similar corrosion behaviors to the candidate CAM were collected from literature. The data are from various exposure conditions in tropical, rural, urban, and industrial test 
locations [2-11]. Important testing parameters considered in the data compilation included test duration, average exposure temperature, average relative humidity, and average sulfur dioxide content of the test atmosphere. The test exposure conditions for the collected data range from 5 to $27^{\circ} \mathrm{C}$ average temperature, 63 to $85 \%$ average relative humidity (RH), and 2 to $406 \mu \mathrm{g} \mathrm{SO} / \mathrm{m}^{3}$ average $\mathrm{SO}_{2}$ content. Although no considerable $\mathrm{SO}_{2}$-level is expected in . the potential repository, it was necessary to include the $\mathrm{SO}_{2}$-content term in the model fitting.

The atmospheric corrosion data include the effects of pollutants such as $\mathrm{SO}_{2}$ and other chemicals in the atmosphere that interact with test specimens. The data also embed any effects of cyclic wetting and drying and salts that may form on the surface of the corroding specimen. Data from marine sites were not included because marine environments are much more corrosive due mostly to the presence of excessive chloride salts in a marine atmosphere and because the post-closure near-field chemical environment is not clear yet, especially for the potential chloride-bearing solid phases derived from the introduced man-made materials and chloride salt concentrations in water contacting waste packages.

\section{Exposure Parameter Transformation}

Exposure conditions of the atmospheric corrosion data fluctuate over periods as short as a day. To develop a humid-air corrosion model using the atmospheric corrosion data, which is applicable to the potential repository environment, it was necessary to transform the collected corrosion data to testing periods, during which corrosion was active. Three relationships were needed to transform the exposure conditions and corrosion data: (1) a relationship to estimate the fraction of the exposure time during which corrosion was active; (2) a relationship to estimate the average relative humidity during that fraction of the time; and (3) a relationship to estimate the average temperature during that fraction of the time. Hourly weather data for a 10-year period from 9 geographical areas covering a wide range of weather conditions from hot and dry to warm and humid to cold and humid were utilized to develop the relationships.

Numerous experimental results from iron specimens exposed to controlled humidity conditions have shown that at about $70 \% \mathrm{RH}$ their surfaces become covered with a 'thin' water film and 'active' corrosion initiates [12,13]. Accordingly, 70\% RH was chosen as the threshold level at which 'active' humid-air corrosion initiates. Using the weather data, a relationship for estimating the fraction of time during which relative humidity is greater than or equal to $70 \%$ was developed as a function of the average relative humidity and average temperature:

$$
f_{70}=\frac{1}{1+\exp \left[1.0362+\frac{27.8249\left(55.3159-R H_{\text {avg }}\right)}{T_{\text {avg }}}\right]}
$$

where $\mathrm{f}_{70}$ is the fraction of time during which $\mathrm{RH} \geq 70 \%, \mathrm{RH}_{\mathrm{avg}}$ is the annual average relative humidity (\%), and $\mathrm{T}_{\text {avg }}$ is the annual average temperature $\left({ }^{\circ} \mathrm{C}\right) . \mathrm{RH}_{\text {avg }}$ and $\mathrm{T}_{\text {avg }}$ are provided with the corrosion data.

A 'new' exposure time of each corrosion data point was estimated by multiplying the actual exposure time with the time fraction during which $\mathrm{RH} \geq 70 \%$, calculated with Eqn. (1). Relationships for a 'new' average relative humidity and 'new' average temperature of each corrosion data for that period of time during which $\mathrm{RH} \geq 70 \%$ were developed utilizing the weather data. The relationship developed for the new average relative humidity is: 


$$
R H_{\text {new }}=83.16-0.1383 R H_{\text {avg }}-0.1057 T_{\text {avg }}+0.002337 R H_{\text {avg }}^{2} \text {. }
$$

where $\mathrm{RH}_{\text {new }}$ is the new average relative humidity (\%). The new average temperature was estimated with the following equation:

$$
T_{\text {new }}=-13.34+0.1514 R H_{\text {avg }}+1.017 T_{\text {avg }}
$$

where $T_{n e w}$ is the new average temperature $\left({ }^{\circ} \mathrm{C}\right)$. The corrosion data collected were transformed using Eqns. (1) to (3), and the new average relative humidity and temperature are assumed to be the representative exposure conditions for the transformed corrosion data.

\section{General Corrosion Model}

The following dependencies of general corrosion on exposure conditions in humid-air were obtained from the literature data and incorporated into the model development.

$$
\begin{gathered}
D_{g} \propto A_{1} t^{A_{2}} \\
\frac{d D_{g}}{d t} \propto B_{1} e^{\frac{B_{2}}{R H}} . \\
\frac{d D_{g}}{d t} \propto C_{1} e^{\frac{C_{2}}{T}} \\
\frac{d D_{g}}{d t} \propto D_{1} e^{D_{2}\left[s O_{2}\right]} .
\end{gathered}
$$

where $D_{g}$ is general corrosion depth $(\mu \mathrm{m}), d D_{g} / d t$ is general corrosion rate $(\mu \mathrm{m} / \mathrm{yr}), t$ is exposure time (years), $\mathrm{RH}$ is relative humidity $(\%), \mathrm{T}$ is temperature $(\mathrm{K})$, and $\left[\mathrm{SO}_{2}\right]$ is sulfur dioxide content in the testing atmosphere $\left(\mu \mathrm{g} / \mathrm{m}^{3}\right)$. A's, B's, C's, and D's are constants. By combining Eqns. (4) through (7)), the humid-air general corrosion model can be expressed as follows:

$$
\ln D_{8}=a_{0}+a_{1} \ln t+\frac{a_{2}}{R H}+\frac{a_{3}}{T}+a_{4}\left[S O_{2}\right]+\varepsilon
$$

where $a_{0}, a_{1}, a_{2}, a_{3}$ and $a_{4}$ are constants to be determined from fitting Eqn. (8) to the transformed corrosion data. $\varepsilon$ is a term representing uncertainties not explained by the model and has a normal distribution with a mean of zero and a standard deviation of 0.38 . Linear regression was used to fit the model in Eqn. (8), giving the following parameter values: $a_{0}=$ $16.9865 \pm 2.8736, a_{1}=0.6113 \pm 0.0295, a_{2}=-893.76 \pm 231.04, a_{3}=-833.53 \pm 381.97$, and $a_{4}$ $=0.002637 \pm 0.000377$. The corrosion data used and the model estimate with its uncertainties $\left( \pm 2\right.$ standard deviations) are shown in Fig. 1. The input parameters $\left(15^{\circ} \mathrm{C}, 84 \%\right.$ $\mathrm{RH}$, and $\left.90 \mu \mathrm{g} \mathrm{SO} / \mathrm{m}^{3}\right)$ for the estimate in the figure are the averages of the data set.

\section{Bitting Corrosion Model}

A stochastic pitting corrosion model for the corrosion-allowance barrier in humid-air was 


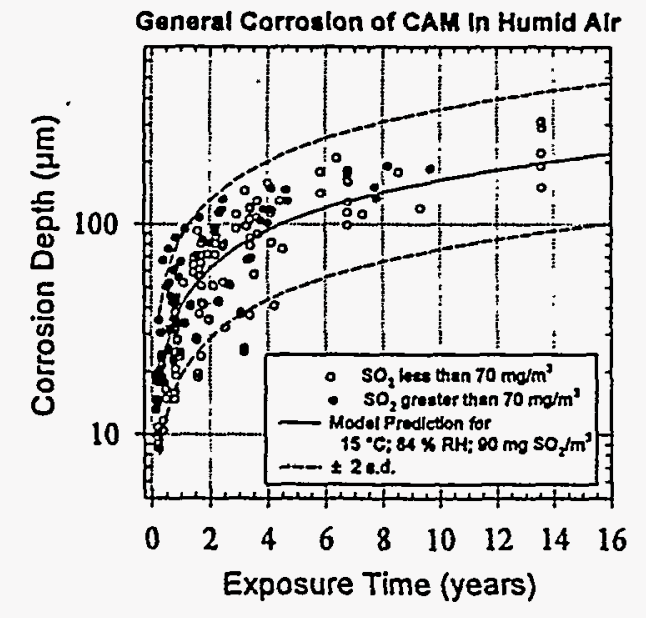

Fig. 1 Atmospheric general corrosion data for CAM and the model estimation with the uncertainty. developed by utilizing a pitting factor that is defined as the ratio of the maximum pit depth to the general corrosion depth at a given exposure time. The results from the extensive corrosion testing programs in inland tropical environments in Panama indicate that the pitting factor for carbon steels and cast irons exposed to 'normal' atmospheric conditions (i.e. in the absence of highly aggressive conditions such as in acidic or concentrated salt conditions) ranged from 2 to $6[7,8]$. The distribution may be similar to a normal distribution but with a long tail to the right [14-16]. Accordingly, the pitting factor was assumed to be normally distributed with a mean of 4 and a standard deviation of 1 . In addition, the pitting factor was constrained to be greater than or equal to 1 , i.e. with the pitting factor equal to 1 , the pit depth is equal to the general corrosion depth. The pitting factor was sampled randomly and

used as a multiplier to the general corrosion depth. Thus, the pitting corrosion model of CAM in humid-air is expressed as follows:

$$
D_{p}=f_{p} \cdot D_{g}=\left\{\begin{array}{cl}
\operatorname{normal}(4,1) \cdot D_{g} & \text { if normal }(4,1) \geq 1 \\
D_{g} & \text { if normal }(4,1)<1
\end{array}\right.
$$

where $D_{p}$ is pit depth $(\mu \mathrm{m})$ and $f_{p}$ is the pitting factọr. In the stochastic pitting modeling, pit initiation was not explicitly considered. Instead, all the pits that can form on the waste container were assumed to start growing at the same time when the humid-air general corrosion initiates.

\section{AQUEOUS CORROSION MODELS}

\section{General Corrosion Model}

An aqueous general corrosion model for CAM was developed using long-term corrosion data for a suite of carbon steel and cast iron, which were obtained from literature. The following aqueous general corrosion dependencies on exposure conditions were obtained from the literature data and incorporated into the model development:

$$
\begin{gathered}
D_{g} \propto A_{3} t^{A_{4}} \\
\frac{d D_{g}}{d t} \propto C_{3} e^{\left(\frac{C_{4}}{T}+C_{3} T^{2}\right)}
\end{gathered}
$$

where A's and C's are constants, and other symbols were defined in Equns. (4) to (7). By combining Eqns. (11) and (12), the aqueous general corrosion model is expressed as follows: 


$$
\ln D_{8}=b_{0}+b_{1} \ln t+\frac{b_{2}}{T}+b_{3} T^{2}+\varepsilon
$$

where $b_{0}, b_{1}, b_{2}$ and $b_{3}$ are constants to be determined from fitting Eqn. (13) to the aqueous general corrosion data. $\varepsilon$ is a term representing uncertainties not accounted for in the model and has a normal distribution with a mean of zero and standard deviation of 0.19 . Parameter values for the corrosion rate constant $\left(b_{0}\right)$ and the time-dependence term $\left(b_{1}\right)$ were determined from long-term corrosion data (up to 16 years) in polluted river water $[17,18]$ and in tropical lake water [19]. The data include the potential effects of various chemical species dissolved and of microbial activity in the waters. Parameter values for the temperature dependence terms $\left(b_{2}\right.$ and $\left.b_{3}\right)$ were determined from a set of short-term (100 days) corrosion data of mild steel in distilled water at temperatures from 5 to $90^{\circ} \mathrm{C}[20,21]$. The parameter values are: $b_{0}$ $=111.506 \pm 10.804, b_{1}=0.532 \pm 0.0272, b_{2}=-23303.2 \pm 2296.2$, and $b_{3}=-3.193 \times 10^{-4} \pm$ $3.526 \times 10^{-5}$. Shown in Fig. 2-(A) are the long-term aqueous general corrosion data in lake water and (polluted) river water, which were used for the model development, and the model estimate with its uncertainty envelope of two standard deviations. The temperature-dependent general corrosion data of mild steel in distilled water are shown in Fig. 2-(B) along with the model estimate with its uncertainty envelope of two standard deviations. The aqueous general corrosion rate of CAM is shown to have a maximum at temperatures between 60 and $70^{\circ} \mathrm{C}$, and this is a result of the combined effects of a decreasing oxygen solubility and an enhanced (dissolved) oxygen diffusivity in water with an increase in temperature.

\section{Pitting Corrosion Model}

As in the humid-air pitting corrosion model, aqueous pitting corrosion of CAM was modeled stochastically by assuming the pitting factor is normally distributed with a mean of 4 and a standard deviation of 1 [19], and Eqn. (9) is also applicable to aqueous pitting corrosion of CAM.
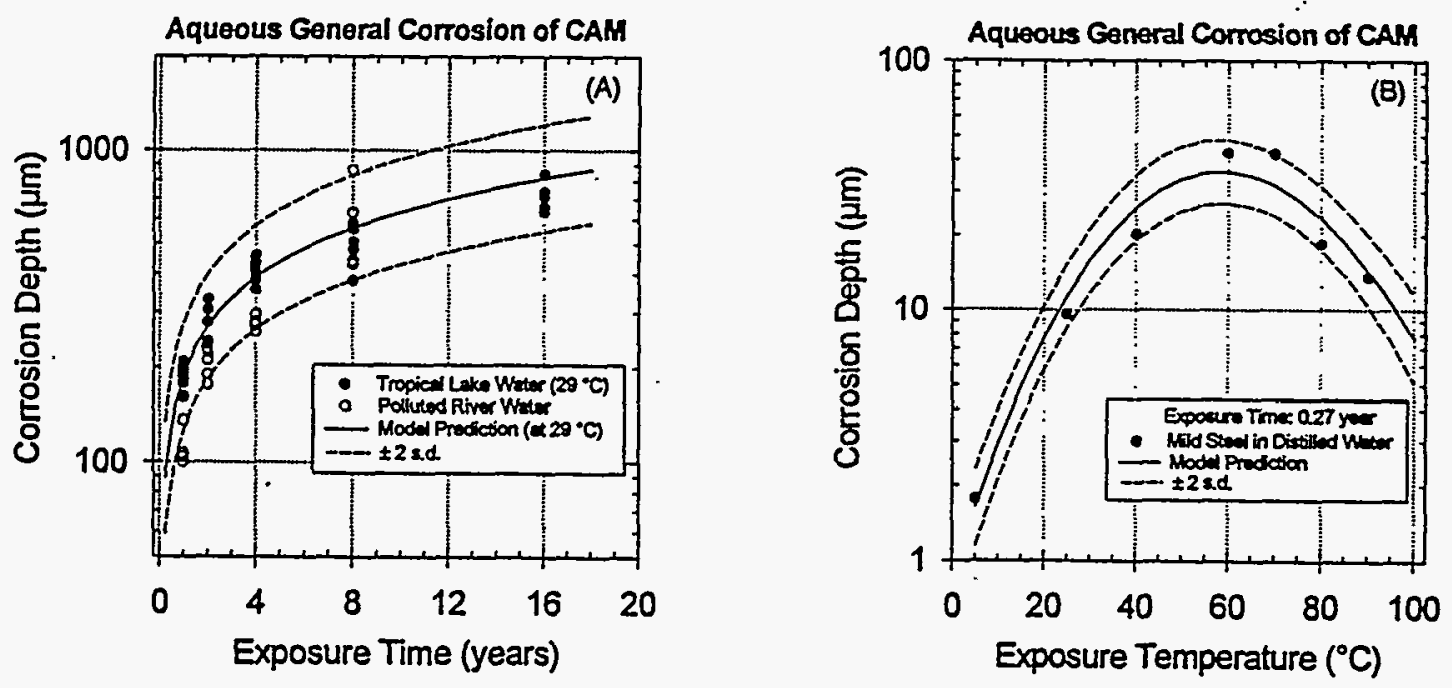

Fig. 2 Aqueous general corrosion data of CAM and the model estimate with uncertainty: (A) corrosion reaction and time dependence; and (B) temperature dependence. 


\section{RESULTS AND DISCUSSION}

All the modeling results discussed below were calculated using the expected values of the parameters in the humid-air general corrosion model, Eqn. (8), and the aqueous general corrosion model, Eqn. (12). Incorporation of the model uncertainties into a stochastic waste package degradation simulation in the potential repository is discussed by Lee, et al. [22].

\section{Humid-Air Corrosion Model Results}

The model predictions for the effects of relative humidity on the general corrosion rate at different exposure times are shown in Fig. 3-(A) for exposure temperature of $90^{\circ} \mathrm{C}$. The results show that the general corrosion rate of CAM is negligible at $\mathrm{RH}$ values less than about $60 \%$. The general corrosion rate becomes significant at about $65 \% \mathrm{RH}$, and increases exponentially with relative humidity above the threshold $\mathrm{RH}$. The corrosion rate decreases with exposiure time, and this is due primarily to corrosion products formed on the bare metal, which act as a barrier to the transport of reacting species. The model predictions are consistent with literature data [12,13]. The model predictions for the effects of $\mathrm{SO}_{2}$ levels in humid-air on the general corrosion of CAM are shown in Fig. 3-(B) for exposure time of one year. The general corrosion rate at $200 \mu \mathrm{g} \mathrm{SO}_{2} / \mathrm{m}^{3}, 90 \% \mathrm{RH}$ and $90^{\circ} \mathrm{C}$ is about twice the general corrosion rate predicted at $90 \% \mathrm{RH}, 90^{\circ} \mathrm{C}$ and no $\mathrm{SO}_{2}$ pollution (shown in Fig. 3(A)). These corrosion behaviors predicted with the current model are consistent with those reported in literature [23-25].
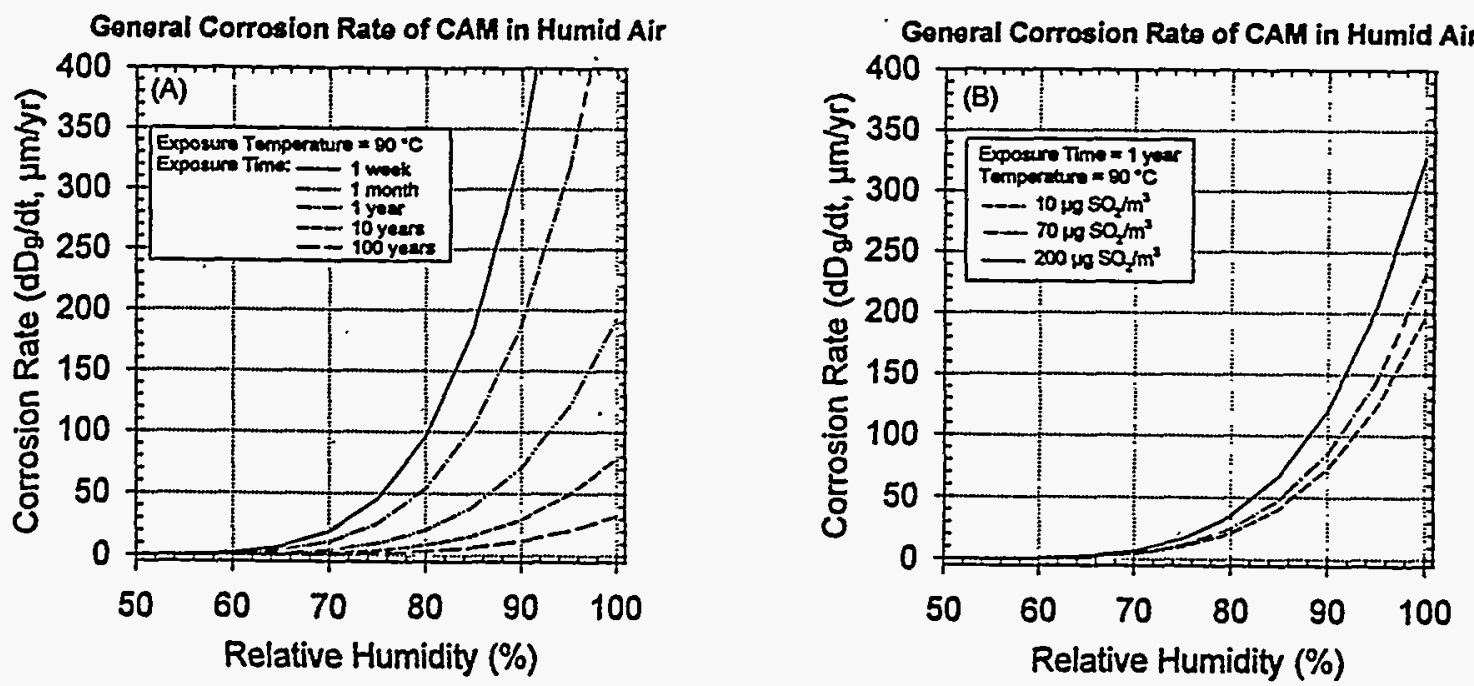

Fig. 3 Model prediction of general corrosion rates of CAM in humid-air at $90^{\circ} \mathrm{C}$ : (A) as a function of $\mathrm{RH}$ at different exposure times (no $\mathrm{SO}_{2}$ effect); and (B) as a function of $\mathrm{RH}$ at different $\mathrm{SO}_{2}$ levels after one year exposure.

In Figs. 4-(A) and (B), the predicted humid-air general corrosion rate of CAM as a function of exposure time at different exposure conditions (i.e., relative humidity and temperature) is compared with the aqueous general corrosion rate (noted as "aqueous corrosion" in the figures) predicted by Eqn. (12). As shown in the figures, within the range of 85 to $100 \% \mathrm{RH}$, the humid-air general corrosion rates are close to the aqueous corrosion rates at the corresponding temperatures. These model predictions are consistent with the 
visual observations that the surface of steel panels tested in a controlled humidity chamber was covered with moisture at about $85 \% \mathrm{RH}$ [26]. The moisture formation is due mostly to capillary condensation of moisture on and hygroscopic nature of corrosion products [26,27].
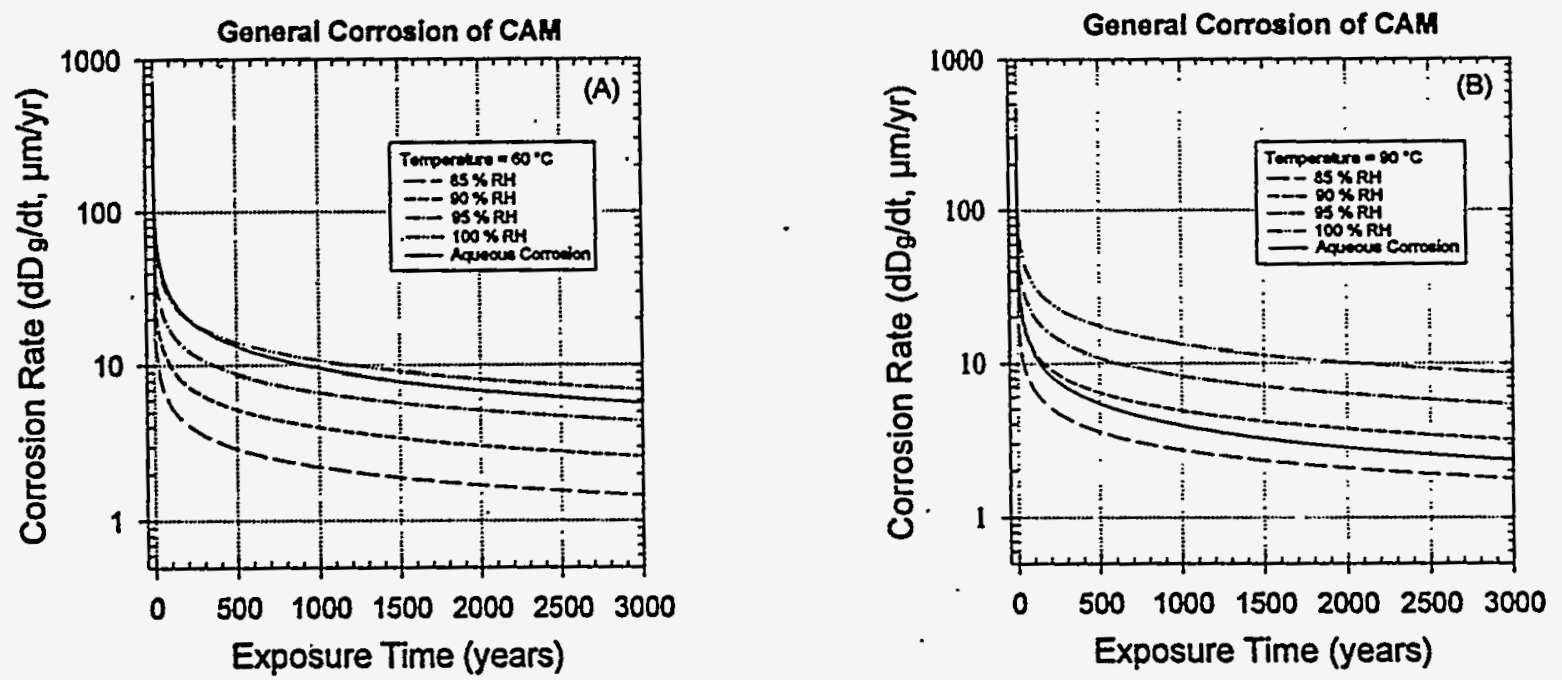

Fig. 4 Comparison of the predicted general corrosion rate of $\mathrm{CAM}$ in humid-air at different relative humidities to the predicted aqueous general corrosion rate at (A) $60^{\circ} \mathrm{C}$ and (B) $90^{\circ} \mathrm{C}$.

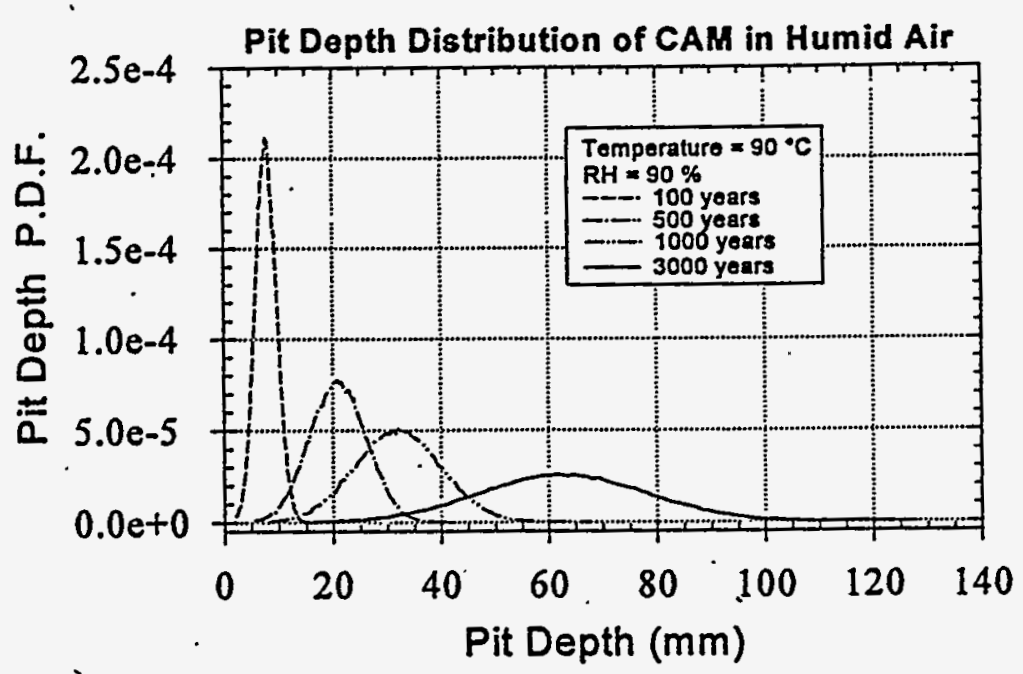

Fig. 5 Model prediction of PDFs of pit depth distribution of CAM in humid-air after different exposure times at $90^{\circ} \mathrm{C}$ and $90 \%$ RH.
The predicted probability density functions (PDFs) of pit depth distribution for $\mathrm{CAM}$ at $90^{\circ} \mathrm{C}$ and $90 \%$ $\mathrm{RH}$ are shown in Fig. 5 for exposure times of up to 3,000 years. The pitting corrosion modeling results were calculated using the expected values of the parameters in the humid-air general corrosion model (Eqn. (8)) and using the pitting factors chosen according to Eqn. (9). Considering a $100-\mathrm{mm}$ thick CAM that is continuously exposed to the constant humid-air condition, the pits would reach up to about 70-mm after 1,000-year exposure and penetrate the CAM thickness within 3,000-year exposure.

\section{Aqueous Corrosion Models}

Predictions of the aqueous general corrosion rate of CAM as a function of exposure time 


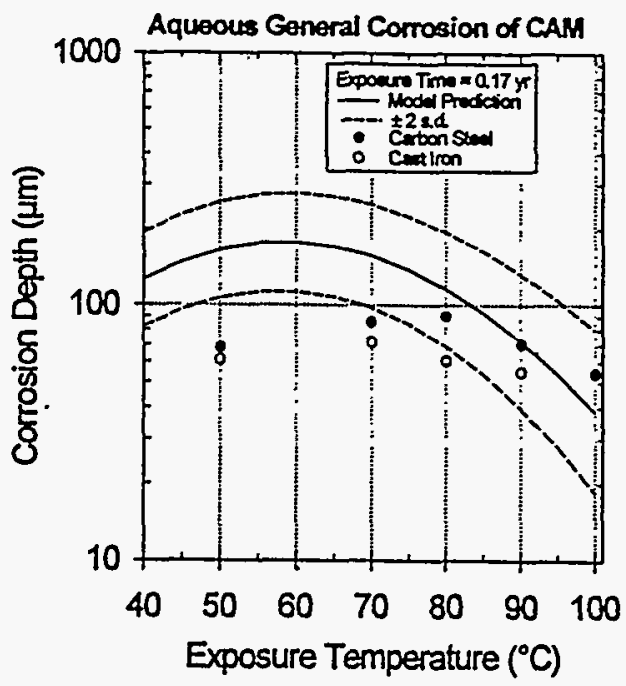

Fig. 6 Comparison of model estimate of aqueous general corrosion of CAM at different temperatures with the data in J-13 water from [28]. at 60 and $90^{\circ} \mathrm{C}$ were shown in Figs. 4-(A) and (B), respectively. Model estimates for the temperature dependence of aqueous general corrosion is compared in Fig. 6 with the general corrosion data of carbon steel and cast iron which were tested in a simulated (and possibly concentrated) J-13 water [28]. Even though the model was developed from different data sources, the model estimates are consistent with the J-13 water general corrosion depth data. Compared to the temperature-dependence of mild steel corrosion in distilled water (Fig. 2(B)), the corrosion data in J-13 water show a weaker temperature dependence. In the corrosion of mild steel in distilled water, dissolved oxygen $\left(\mathrm{O}_{2}(\mathrm{aq})\right)$ and, to a lesser extent, hydrogen ion $\left(\mathrm{H}^{+}\right.$(aq)) in the water may have been the major species that participated in the corrosion reduction reactions [21]. For the corrosion in J-13 water, other species (mostly carbonate species $[29,30]$ and nitrate ions [20]),

in addition to dissolved oxygen and hydrogen ion, may also have participated in the corrosion reduction reactions. These additional reduction reactions would result in the weaker temperature dependence of general corrosion in J-13 water.

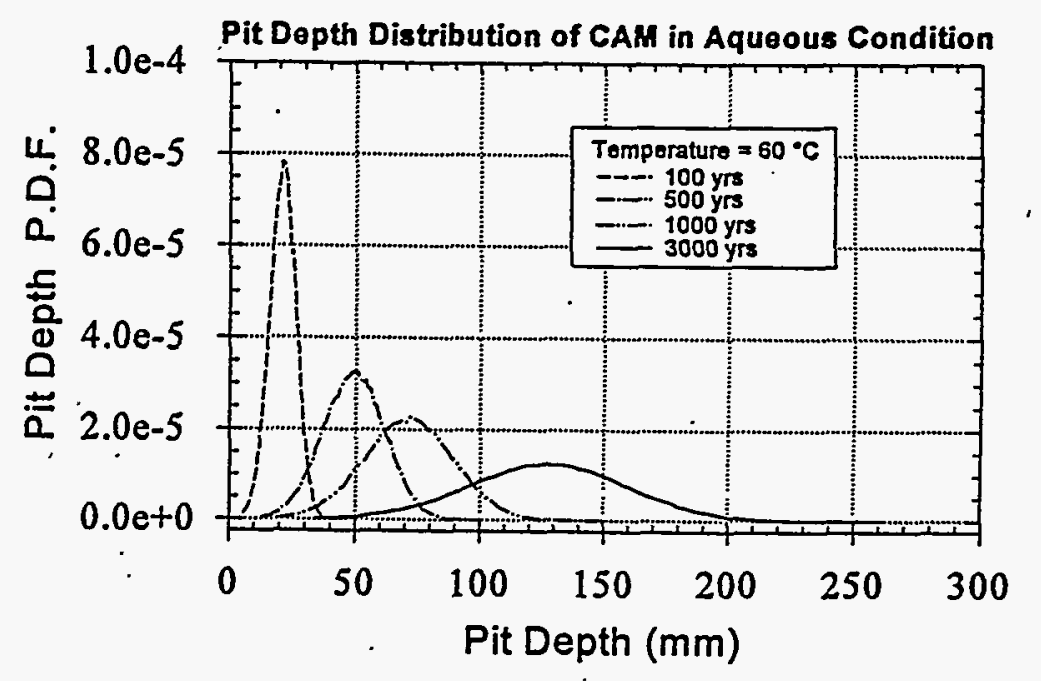

Fig 7. Model prediction of PDFs of pit depth distribution of CAM in aqueous condition at $60^{\circ} \mathrm{C}$ and different exposure times.
Probability density functions (PDFs) of pit depth distribution for CAM exposed to a constant aqueous condition at $60^{\circ} \mathrm{C}$ for different exposure times are shown in Fig. 7. It was shown in Fig. 2-(B) that $C A M$ has a maximum corrosion rate at about $60^{\circ} \mathrm{C}$. The calculations were performed using the expected values of the parameters of the aqueous general corrosion model (Eqn. (12)) and using the pitting factors chosen as in Eqn. (9). The results indicate a $100-\mathrm{mm}$ thick CAM outer containment barrier may have the first pit penetration as early as 500 years if the near-field environment maintains aqueous conditions at about $60^{\circ} \mathrm{C}$. 
The humid-air general corrosion model (including the uncertainties) for the carbon steel corrosion-allowance outer barrier material was developed using a total of 166 atmospheric corrosion data points (up to 16 years of exposure time) for a suite of cast iron and carbon steel. The atmospheric corrosion data incorporate the effects of pollutants such as $\mathrm{SO}_{2}$ and other chemicals in the atmosphere that interact with test specimens. The data also embed the effects of cyclic wetting and drying and salts that may form on the surface of the corroding specimen. The aqueous general corrosion model (including the uncertainties) for the outer barrier was developed as a function of exposure time and temperature using the data from literature. The data include the potential effects of various chemical species dissolved and of microbial activity in the waters. Pitting corrosion of the outer barrier in a humid-air or aqueous condition was modeled by assuming the pitting factor is normally distributed with a mean at 4 and a standard deviation of 1 . The pitting factor was sampled randomly and used as a multiplier to the humid-air or aqueous general corrosion depth at a given time.

The humid-air corrosion model predicts that an 'active' humid-air corrosion initiates at about $65 \% \mathrm{RH}$, and the general corrosion rate increases exponentially with relative humidity above the threshold RH. Predictions of the humid-air and aqueous general corrosion models are consistent in that the predicted humid-air general corrosion rates at relative humidities between 85 and $100 \% \mathrm{RH}$ are close to the predicted aqueous general corrosion rates. These predicted behaviors are also consistent with those reported in literature [26].

Using the expected values of the model parameters and assuming a constant humid-air or aqueous exposure condition, the model predicts a $100-\mathrm{mm}$ thick CAM outer barrier may not fail in humid-air corrosion conditions until up to about 3,000 years. Aqueous pitting corrosion is the most likely failure mode for the CAM barrier, and an earliest failure (or initial pit penetration) may occur as early as about 500 years if it is exposed continuously to an aqueous condition at between 60 and $70^{\circ} \mathrm{C}$.

\section{ACKNOWLEDGEMENTS}

This work was funded by the US DOE Yucca Mountain Site Characterization Office under Contract \#DE-AC01-91RW00134 to TRW Environmental Safety systems, Inc.

\section{REFERENCES}

1. CRWMS M\&O, Total System Performance Assessment-1995: An Evaluation of the Petential Yucca Mountain Repository, B00000000-01717-2200-00136, Rev. 01, Nov. 1995.

2. F.H. Haynie, and J.B. Upham, Mat. Pro. Perf., 10, p.'18 (Nov. 1971).

3. D. Knotkova, P. Holler, and J. Vickova, in Procd. of the 8th Int'l Congr on Metallic Corrosion, Sept. 6-11, Mainz, FRG, Vol. 1,.p. 859 (1981).

4. D. Knotkova-Cermakova, J. Vickova, and J. Honzak, in Atmospheric Corrosion of Metals, ASTM STP 767, edited by S. W. Dean, Jr. and E. C. Rhea, ASTM, 1982, p. 7.

5. M.E. Komp, M. E., Mater: Perf., p. 42 (July 1987).

6. D. Pereira, O. Nobre, and E. Almeida, in Progr in the Understanding and Prevention of Corrosion, edited by J.M. Costa and A.D. Mercer, Vol. 1, p. 66 (1993). 
7. C.R. Southwell, and J.D. Bultman, in Atmospheric Corrosion, edited by W.H. Ailor, Wiley, 1982, p. 943.

8. C.R. Southwell, J.D. Bultman, and A.L. Alexander, Mater. Perf., p. 9, (July 1976).

9. H.E. Townsend, and J.C. Zoccola, in Atmospheric Corrosion of Metals, ASTM STP 767, edited by S.W. Dean, Jr. and E.C. Rhea, ASTM, 1982, p. 45.

10. N.Q. Tri, V.D. Huy, L.V. Cuong, and P.Th. San, in Progress in the Understanding and Prevention of Cerrosion, edited by J.M. Costa and A.D. Mercer, Vol. 1, p. 105 (1993).

11. F.I. Wei, Brit. Corr. J., 26, p. 209 (1991).

12. W.H. Vernon, Trans. Electrochem. Soc., 64, p. 31 (1933).

13. P.B. Phipps, and D.W. Rice, in Corrosion Chemistry, edited by G.R. Brubaker, and P.B. Phipps, ACS Symp. Ser. 89, Am. Chem. Soc., 1979, p. 235.

14. G.P. Marsh, and K.J. Taylor, Corr. Sci., 28, p. 289 (1988).

15. G.P. Marsh, K.J. Taylor, and Z. Sooi, SKB. Technical Report 88-09 (Feb. 1988).

16. J.E. Strutt, J.R. Nichols, and B. Barbier, Corr. Sci., 25, p. 305 (1985):

17. C.P. Larrabee, Corrosion, 9, p. 259 (1953).

18. S.K. Coburn, Metals Handbook (9th Ed.), ASM, Vol.1, p.733 (1978).

19. C.R. Southwell, and A.L. Alexander, Mater. Protection, p. 14 (Jan. 1970).

20. D.M. Brasher, and A.D. Mercer, Brit. Corr. J., 3, p. 121 (1968).

21. A.D. Mercer, I.R. Jenkins, and J.E. Rhoades-Brown, Brit. Corr. J.,3, p. 136 (1968).

22. J.H. Lee, J.E. Atkins, and R.W. Andrews, this volume.

23. H. Guttman, and P.J. Sereda, Metal Corrosion in the Atmosphere, ASTM STP 435, 1968, p. 326.

24. F.H. Haynie, and J.B. Upham, Corrosion in Natural Environments, ASTM STP 558, 1974, p. 33.

25. V. Kucera, and E.Mattsson, Corrosion in Natural Environments, ASTM STP 558, 1974, p. 239.

26. F.H. Haynie, J.W. Spence, and J.B. Upham, in Atmospheric Factors Affecting the Corresion of Engineering Metals, ASTM STP 646, edited by S.K. Coburn, 1978, p. 30.

27. D. Fyfe, in Corrosion. Vol 1-Metal/Environment Reactions, 3rd Ed., edited by L.L. Shreir, R.A. Jarman, and G.T. Burstein, Butterworth-Heinemann, p. 2:31 (1994).

28. R.D. McCright, and H. Weiss, in Scientific Basis for Nuclear Waste Management VIII, edited by C.M. Jantzen, J.A. Stone and R.C. Ewing, Mat. Res. Soc. Sym. Proc. 44, Pittsburg, PA, 1985, p. 287.

29. K. Masamura, and I. Matsushima, Trans. Iron \& Steel Inst. Japan, 23, p. 676 (1983).

30. S. Nesic, in Progress in the Understanding and Prevention of Corrosion, edited by J.M. Costa and A.D. Mercer, Vol. 1, p. 539 (1993).

\section{DISCLAIMER}

This report was prepared as an account of work sponsored by an agency of the United States Government. Neither the United States Government nor any agency thereof, nor any of theiremployees, makes any warranty, express or implied, or assumes any legal liability or roduct, or bility for the accuracy, completeness, or usefulness of any information, apparatus, product, or process disclosed, or represents that its use would not infringe privately owne rame, trademark, ence herein to any specific commercial product, process, or ser imply its endorsement, recommanufacturer, or otherwise does not necessarily constitute or imply its endorect the views mendation, or favoring by the United States Government or any agency thereof. The vithe

and opinions of authors expressed herein do not 